\title{
Application Analysis of Medium Temperature Solar Refrigeration System in Civil Buildings
}

\author{
Denghui JIANG, Ning LIU1', Huakai LIU and Xiao LI \\ Solar Products Testing Center, Shandong Institute for Product Quality Inspection, \\ Jinan, Shandong, China
}

\begin{abstract}
The lithium bromide absorption refrigeration system with medium temperature solar collector as driving heat source was built, and the refrigeration performance of the system was tested and analyzed. The medium-temperature solar collector adopts all-glass vacuum solar collector tube with heat-conducting oil as medium, and the inside of the vacuum tube is composed of heat-conducting medium flow channel on the sunny side and aluminum silicate insulation cotton on the backlight side. Through test and analysis, the medium temperature solar collector of the system can provide stable heat source, and the maximum temperature of solar heating can reach above $150^{\circ} \mathrm{C}$ in sunny weather and about $80^{\circ} \mathrm{C}$ in cloudy days. The generator driving heat of the system is stable and efficient. The driving heat of lithium bromide absorption refrigerator is higher than $200 \mathrm{MJ} / \mathrm{h}$, and can reach 300 $\mathrm{MJ} / \mathrm{h}$ in some periods. The COP of the system can be kept above 0.6 during stable operation, but when the driving temperature of the generator is higher than $80^{\circ} \mathrm{C}$, the COP of the system basically does not increase with the increase of the driving temperature.
\end{abstract}

Keywords. Solar refrigeration system, lithium bromide, all-glass vacuum solar collector

\section{Introduction}

With the development of economy and society, the world is facing increasingly severe environmental problems. The Paris Climate Agreement, which was adopted at the Paris Climate Change Conference in December 2015 and signed in New York in April 2016, requires participating countries to strengthen the global response to the threat of climate change, control the global average temperature rise within $2^{\circ} \mathrm{C}$ compared with the preindustrial level, and strive to control the temperature rise within $1.5^{\circ} \mathrm{C}$. Only when the global greenhouse gas emission reaches its peak as soon as possible and the net zero emission of greenhouse gas is realized in the second half of this century can the ecological risk brought by climate change to the earth and the survival crisis brought to mankind be reduced. As a responsible big country, in September 2020, at the 75th United Nations General Assembly, China solemnly announced to the world that it would increase its contribution to national independent emission reduction, and strive to reach its peak before 2030, and strive to achieve carbon neutrality before 2060 . In order to fulfill its promise, China needs to reduce energy consumption in all fields.

1 Corresponding Author, Ning LIU, Solar Products Testing Center, Shandong Institute for Product Quality Inspection, Jinan, Shandong, China; Email: liuning@sdqi.com.cn. 
Taking civil buildings as an example, the energy consumption of buildings accounts for $40 \%$ of the total energy consumption of the whole society and is still growing rapidly [1-3] Reducing air conditioning energy consumption in buildings can effectively alleviate the growth rate of building energy consumption. On the other hand, with the progress of technology, the heat collection efficiency of solar collectors has been continuously improved and the production cost has been continuously reduced, the application field of solar heat collection engineering is expanding from solar hot water to solar air conditioning, heating, and industrial and agricultural fields, and the heat consumption temperature has also increased from low temperature to medium temperature above $100^{\circ} \mathrm{C}$. To sum up, the lithium bromide absorption refrigeration and air conditioning technology using the medium temperature solar collector as the driving heat source has broad development prospects.

Li et al. [4] made use of a $25-\mathrm{kW}$ solar lithium bromide absorption refrigerator, and based on considering environmental conditions, refrigerating capacity, COP and heat collection area, simulated and verified the generator driving temperature, cooling water inlet temperature and refrigerant water outlet temperature. The results showed that the generator driving temperature, cooling water inlet temperature and refrigerant water outlet temperature were $66^{\circ} \mathrm{C} \sim 71^{\circ} \mathrm{C}, 25^{\circ} \mathrm{C} \sim 30^{\circ} \mathrm{C}$ and $14^{\circ} \mathrm{C} \sim 17^{\circ} \mathrm{C}$, respectively. Xu et al. [5] developed a lithium bromide absorption refrigeration cycle, which can automatically adjust COP according to the heat source temperature, and can ensure COP of $0.3 \sim 0.7$ at the cooling water temperature of $32^{\circ} \mathrm{C} \sim 40^{\circ} \mathrm{C}$. Fong et al. [6] studied the solar refrigeration system under different environmental conditions, and obtained the best refrigeration effect with lithium bromide-water solution as refrigerant.

At present, the lithium bromide absorption refrigeration system with medium temperature solar collector as driving heat source is still mainly based on experimental research, and the medium temperature solar refrigeration system that can be applied in practice is relatively scarce. In this paper, all-glass vacuum solar collector tube type medium temperature solar collector with heat transfer oil as medium is adopted, and the collectors are in series-parallel structure $(8 * 30$ sets $)$, with a total of 240 sets. The inside of the vacuum tube is composed of a heat-conducting medium channel on the sunny side and aluminum silicate insulation cotton on the backlight side, which is matched with a lithium bromide absorption refrigerator with a refrigeration power of $58 \mathrm{~kW}$ to meet the actual refrigeration needs of users.

\section{System Introduction}

As shown in figures 1 and 2, the medium temperature solar absorption refrigeration system consists of a medium temperature solar collector, a hot water tank, a lithium bromide absorption refrigerator, a plate heat exchanger and other auxiliary equipment. The system uses all-glass vacuum solar collector tube type medium temperature solar collector to collect heat, uses heat transfer oil as heat transfer medium, and uses plate heat exchanger to transfer heat to hot water tank, which provides driving heat source for generator of lithium bromide absorption refrigerator, To maintain the normal operation of the refrigerator, the specific working principle of the refrigerator is that the lithium bromide dilute solution in the generator is heated by the heat medium water in the hot water tank, and then becomes a concentrated lithium bromide solution and enters the absorber, the high-temperature and high-pressure water vapor generated by heating and vaporization is used as the refrigerant, and the water vapor enters the condenser for 
temperature reduction and phase change to become high-pressure and low-temperature saturated water, when the saturated water enters the evaporator through the throttle valve, it is rapidly reduced in pressure and vaporized to generate heat absorption effect, thus absorbing the heat of refrigerant to achieve the purpose of refrigeration. The vaporized low-temperature steam enters the absorber, is absorbed by the concentrated lithium bromide solution, and becomes a dilute lithium bromide solution to complete a set of refrigeration cycles.

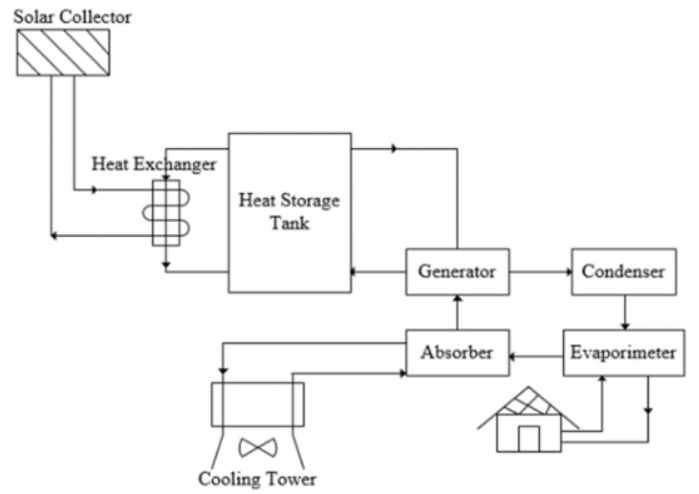

Figure 1. Diagram of medium temperature solar refrigeration system.

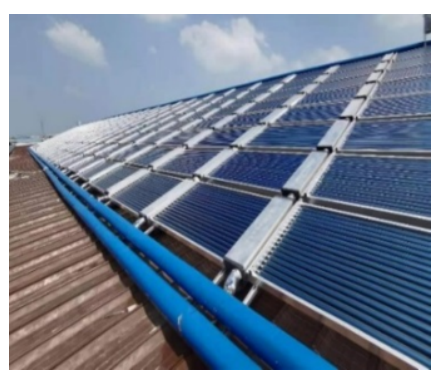

(a) Medium temperature solar collector

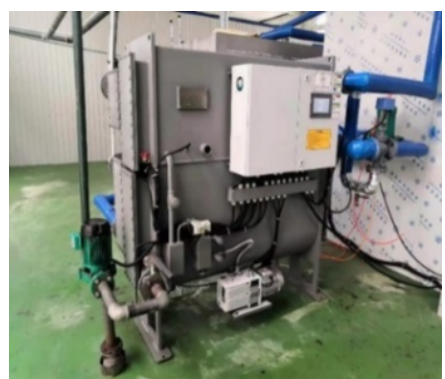

(b) Lithium bromide absorption refrigeration

Figure 2. Snapshot of medium temperature solar refrigeration system.

For the medium-temperature solar collector with vacuum tube, its heat transfer process is a complex transient heat transfer process including heat conduction, convection and radiation [7-9], the medium-temperature solar collector has no reflector, and the vacuum collector tube on the backlight side will be regarded as a pure radiator. Drawing lessons from the research of Zhang [10] on the trough focused solar collector, besides the opening of the light gathering place on the straight-through cavity absorber, laying the arc-shaped insulation layer on the outside of the cavity absorber can effectively reduce the convection and radiation heat loss of the environment on the outside of the absorber. As shown in figure 3, an all-glass vacuum collector tube with an outer diameter of $58 \mathrm{~mm}$ is used in the middle temperature solar collector tube, and the selective absorption layer is coated by magnetron sputtering, a heat-conducting medium flow channel is installed under the selective absorption layer on the sunny side in the vacuum tube cavity, which is a u-shaped tube with heat-conducting oil flowing inside, and an aluminum alloy shell is surrounded by the outside of the flow channel, and the upper 
wall of the shell is closely attached to the selective absorption layer, and the shell area accounts for about one fourth of the area of the selective absorption layer. The remaining space in the middle temperature solar collector tube cavity is filled with aluminum silicate insulation cotton, which effectively reduces convection and radiation heat loss.

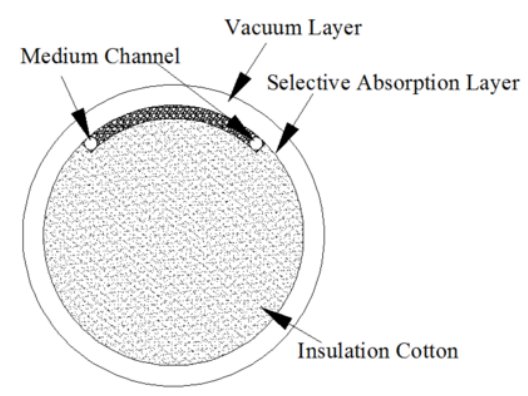

Figure 3. Structure diagram of all-glass vacuum collector tube.

\section{Analysis of System Application}

According to the different irradiation amount on that day, the working performance of the medium temperature solar absorption refrigeration system is tested by selecting four typical working conditions, and the specific weather conditions of the typical working conditions are shown in following table 1.

Table 1. Typical weather conditions.

\begin{tabular}{llll}
\hline Date & Weather conditions & Ambient temperature $\left({ }^{\circ} \mathbf{C}\right)$ & Irradiation amount $\left(\mathbf{M J} / \mathbf{m}^{\mathbf{2}}\right)$ \\
\hline July 28th & Sunny to Cloudy & $22.3 \sim 33.3$ & 18.94 \\
August 3rd & Cloudy to Rain & $26.7 \sim 34.8$ & 13.45 \\
August 5th & Cloudy & $25.8 \sim 29.6$ & 4.44 \\
August 18th & Sunny & $25.3 \sim 36.8$ & 23.32 \\
\hline
\end{tabular}

According to the actual refrigeration demand of the refrigeration demander, the running time of the medium temperature solar refrigeration system is from 8:00 to 17:00 every day, and the system stops running at other times. According to the operation conditions of the system under different weather conditions, the parameters such as working medium temperature, working medium flow rate and meteorological data are collected and calculated and processed, and the processing results of the parameters will be studied and analyzed below.

\subsection{Typical Day Real-Time Temperature Curve}

It can be seen from figure 4 that, thanks to the medium-temperature solar collector mentioned above, the maximum temperature of solar heating can reach above $150^{\circ} \mathrm{C}$ on the sunny day of August 18th, and even on the cloudy day as shown in August 5th, the maximum temperature of solar heating can reach about $80^{\circ} \mathrm{C}$, the medium-temperature solar collector can provide a stable heat source for the system. The water tank temperature under four typical working conditions can be kept above $70^{\circ} \mathrm{C}$, and the maximum temperature can reach $90^{\circ} \mathrm{C}$, which effectively avoids the influence of 
unstable and discontinuous irradiation and low instantaneous energy of the medium temperature solar collector, and is higher than the generation temperature of single-effect lithium bromide absorption refrigeration unit, the COP under different generation temperatures will be further analyzed below. The outlet temperature of refrigerant is kept within the range of about $18^{\circ} \mathrm{C}$, which can provide stable cooling capacity for users.

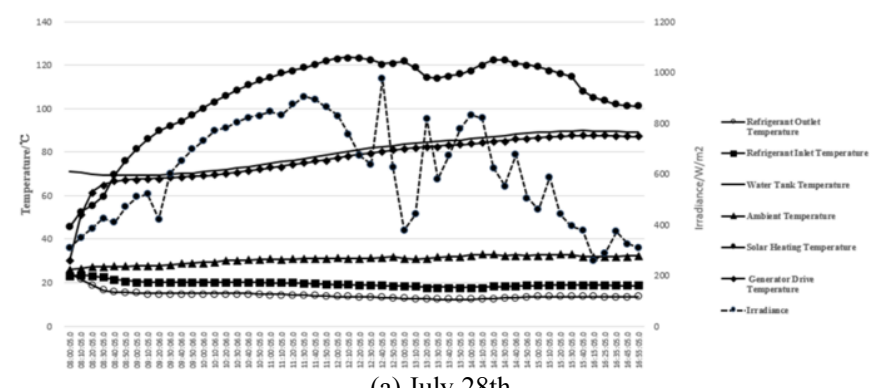

(a) July 28 th
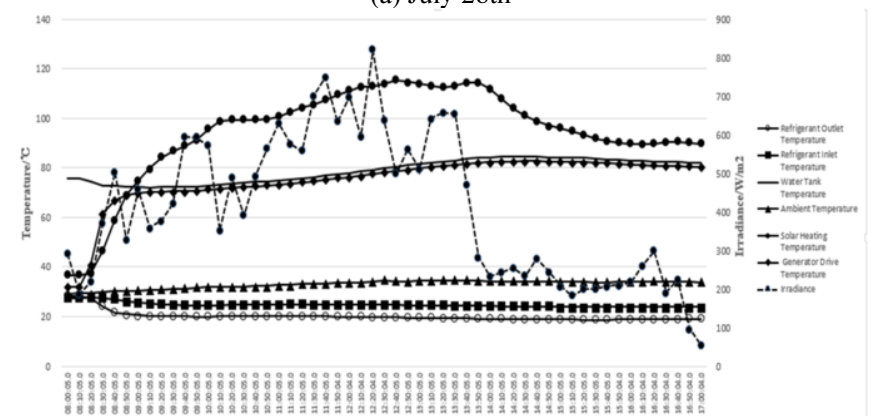

(b) August 3rd
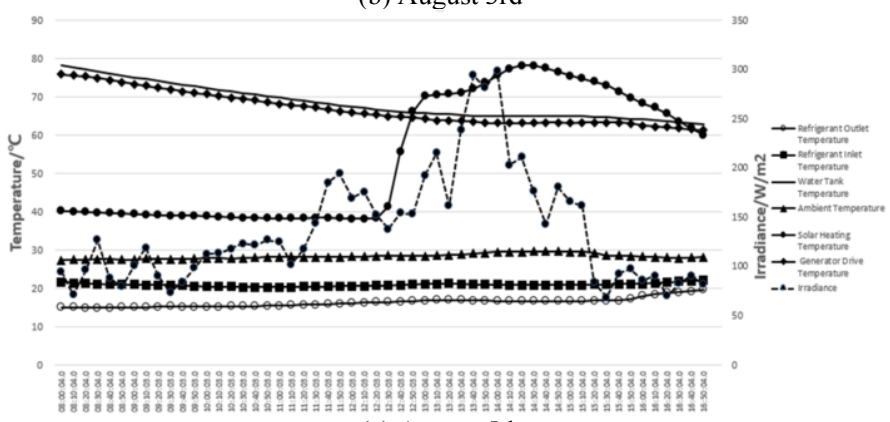

(c) August 5th

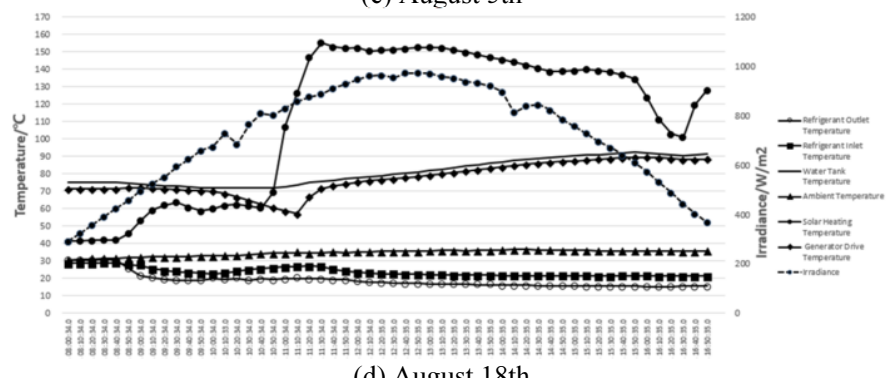

(d) August 18th

Figure 4. Temperature curve of typical day. 


\subsection{Analysis of Refrigeration under Typical Working Conditions}

It can be seen from figure 5 that the generator driving heat of the medium temperature solar refrigeration system is stable and efficient. When the weather is fine, the driving heat of the lithium bromide absorption refrigerator of the system is higher than $200 \mathrm{MJ} / \mathrm{h}$, and can reach $300 \mathrm{MJ} / \mathrm{h}$ in some periods. In bad weather, the driving heat of the system is less than $200 \mathrm{MJ} / \mathrm{h}$ due to insufficient solar heat collection capacity, and mainly depends on the heat release from the water tank, the water capacity of the water tank is $14.5 \mathrm{t}$, which can maintain the refrigeration demand during the working period. If the system runs stably all day, it is necessary to add heat storage and cold storage devices. At present, the project has been equipped with valley electricity storage and cooling devices respectively. It is planned to use low-cost valley electricity storage energy at night and cooperate with medium-temperature solar collectors to complete continuous and stable refrigeration throughout the day, however, due to the fact that the industrial and commercial time-of-use electricity price policy has not been implemented at the project site, the medium-temperature solar refrigeration system has not yet run the heat storage and cooling devices.

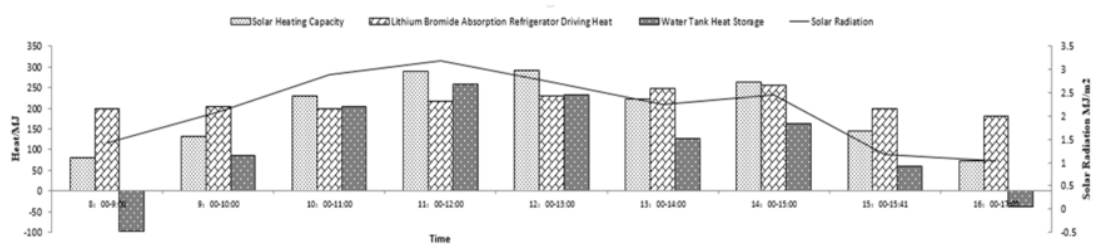

(a) July 28th

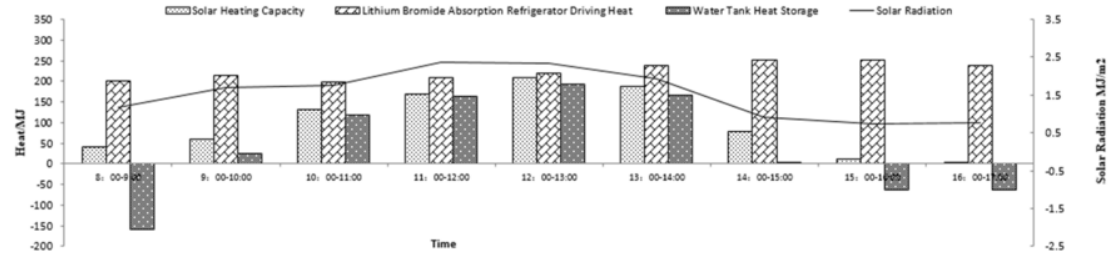

(b) August 3rd

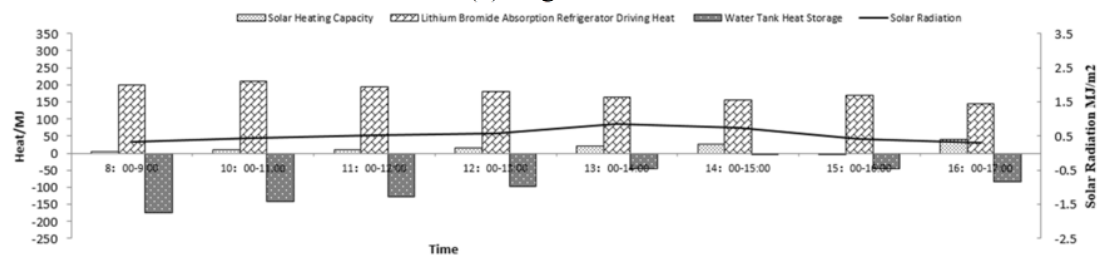

(c) August 5th

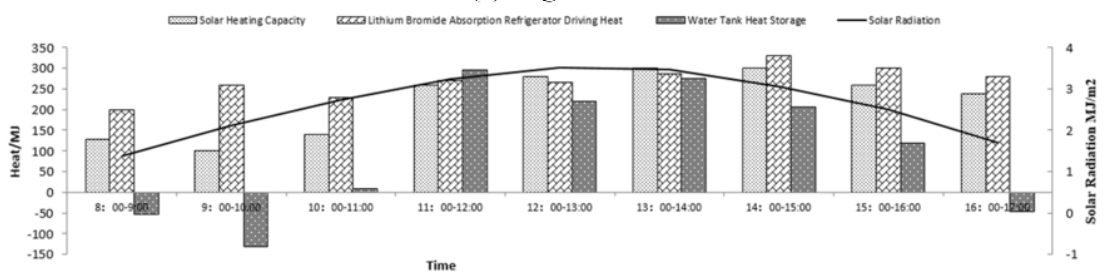

(d) August 18th

Figure 5. Heat supply under typical conditions. 


\subsection{System COP under Typical Operating Conditions}

It can be seen from figure 6 that the system COP increases with the increase of generator driving temperature. When the generator driving temperature is higher than $60^{\circ} \mathrm{C}$, the system COP can basically remain above 0.6 , which is in normal mode. When the generator driving temperature is higher than $80^{\circ} \mathrm{C}$, the system COP basically does not increase, indicating that for single-effect absorption refrigerator, too high generator driving temperature is meaningless to improve the system COP. For single-effect lithium bromide refrigerator, the driving temperature of generator is $60^{\circ} \mathrm{C}-75^{\circ} \mathrm{C}[4]$, and COP increases with the increase of driving temperature, but when the driving temperature is too high, it will have no effect on the growth of system COP. The system needs to be further equipped with heat storage devices to store excess solar heat supply when the solar radiation is high, and to supplement the system heat when the solar radiation is low, so as to ensure that the system is not disturbed by weather changes and the system COP is in a stable and reasonable state.

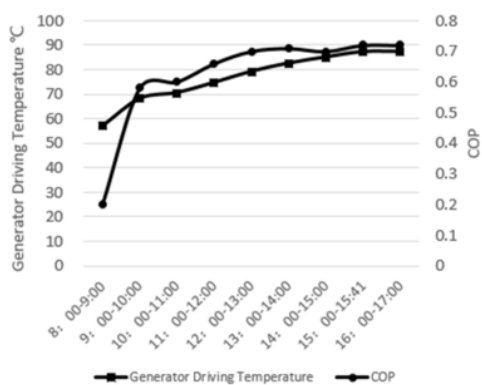

(a) July 28 th

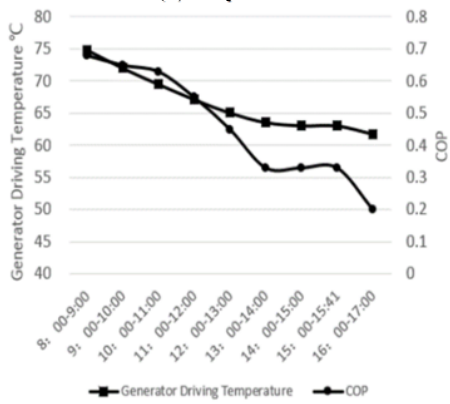

(c) August 5th

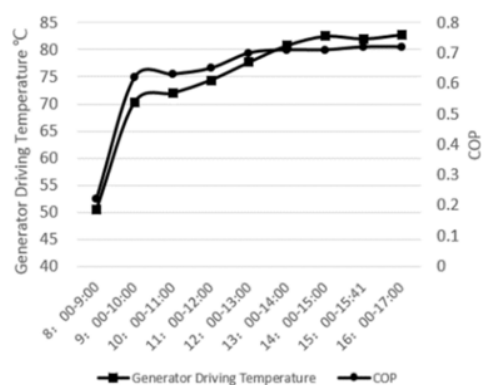

(b) August 3rd

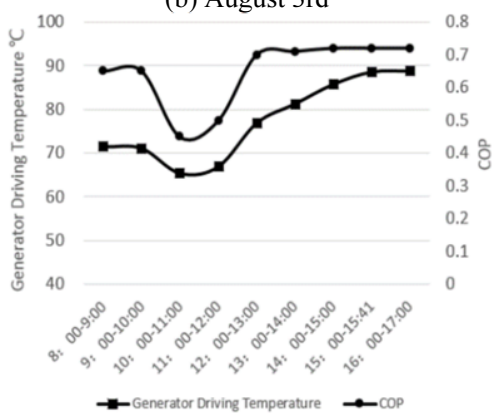

(d) August 18th

Figure 6. Relationship between generator driving temperature and COP under typical conditions.

\section{Conclusion}

The medium temperature solar collector of medium temperature solar absorption refrigeration system can provide stable heat source. The maximum temperature of solar heating can reach above $150^{\circ} \mathrm{C}$ in sunny weather and about $80^{\circ} \mathrm{C}$ in cloudy days. The temperature of the heat storage tank can be kept above $70^{\circ} \mathrm{C}$, and the maximum temperature can reach $90^{\circ} \mathrm{C}$, thus effectively avoiding the influence of unstable and discontinuous irradiation on solar energy. 
The generator driving heat of the medium temperature solar refrigeration system is stable and efficient. When the weather is fine, the driving heat of the lithium bromide absorption refrigerator of the system is higher than $200 \mathrm{MJ} / \mathrm{h}$, and can reach $300 \mathrm{MJ} / \mathrm{h}$ in some periods. When the weather is bad, the heat source driven by the generator of the lithium bromide refrigerator mainly depends on the heat release from the water tank due to the lack of solar heat collection capacity.

The COP of the system can be kept above 0.6 during stable operation, which keeps the ideal working state. However, when the weather is fine, the driving temperature of the generator is sometimes higher than $80^{\circ} \mathrm{C}$, and the $\mathrm{COP}$ of the system basically does not increase with the increase of the driving temperature, which results in that part of the heat cannot be used effectively and reduces the comprehensive efficiency of the system.

In order to realize the all-glass vacuum solar collector tube type solar collector driving the lithium bromide absorption refrigerator to work, a heat-conducting medium runner is installed under the selective absorption layer on the sunny side in the vacuum tube cavity, which is a U-shaped tube with heat-conducting oil circulating inside, and the rest space in the vacuum tube cavity is filled with aluminum silicate insulation cotton. It can effectively reduce convection and radiation heat loss, and can replace the trough solar collector to provide heat source for solar refrigeration system, and improve the system cost performance. However, the system does not run continuously for a long time, and its long-term operation stability needs further testing and analysis.

\section{Acknowledgement}

Funding: (1) National Key Research and Development Program "Research on key technical standards of solar thermal power generation and heat utilization (2017YFF0208300)". (2) Major scientific and technological innovation projects in Shandong Province "Research and application of intelligent combined cooling and heating system coupled with solar energy and various heat pumps (2019JZZY020801).

\section{References}

[1] Muye J, Ayou D S, Saravanan R and Coronas A 2016 Performance study of a solar absorption powercooling system Applied Thermal Engineering 59-67.

[2] Aliane A, Abboudi S, Seladji C and Guendouz B 2016 An illustrated review on solar absorption cooling experimental studies Renewable \& Sustainable Energy Reviews 65 (Nov) 443-458.

[3] Fong K F, Lee C K and Chow T T 2012 Comparative study of solar cooling systems with buildingintegrated solar collectors for use in sub-tropical regions like Hongkong Applied Energy 90 (1) 189-195.

[4] Li P T, Tian R, Xin H and Wang Z M 2019 Parameter selection and verification of household solar refrigeration system Journal of Engineering for Thermal Energy and Power 34 (04) 122-126.

[5] Xu Z Y, Wang R Z and Xia Z Z 2014 Analysis of a 0.n-effect LiBr/Water Absorption refrigeration cycle Journal of Refrigeration 35 (01) 1-7.

[6] Fong K F, Chow T T, Lee C K, Lin Z and Chan L S 2010 Comparative study of different solar cooling systems for buildings in subtropical city Solar Energy 84 (2) 227-244.

[7] Zhang T, Han J T, Yan S Y, Yu Z T and Yue X Y 2015 Simulation and experimental analysis of convection in solar evacuated tube Journal of Engineering Thermophysics 36 (12) 2027-2031.

[8] Zhao D 2013 Numerical Study on the Thermal Performance of U-Tube Solar Collector (Dalian University of Technology).

[9] Huang X 2018 Thermal Radiation Heat Loss Structure Optimization and Performance Analysis of Medium and High Temperature Solar Evacuated Collector Tube (University of Science and Technology of China).

[10] Zhang L Y 2008 Study on Prabolic through Solar Collection and Its Utilization (Shanghai: Shanghai Jiao Tong University). 